\title{
Kajian Pengaruh Bobot Kokon Induk Terhadap Kualitas Telur Persilangan Ulat Sutera (Bombyx mori L.) Ras Jepang Dengan Ras Cina
}

\author{
Y. C. Endrawati ${ }^{1)}$, H. C. H. Siregar ${ }^{1)}$ dan M. Kaomini ${ }^{2)}$ \\ 1) Departemen Ilmu Produksi dan Teknologi Peternakan IPB \\ ${ }^{2)}$ Pusat Penelitian dan Pengembangan Hutan dan Konservasi Alam, Bogor
}

\begin{abstract}
Uniformity of cocoon weight is one important factor of parent stock in order to get a good quality of crosses. In consequence, some cocoons that too heavy or light become wastes even come from a good strain. The research that conducted at Forest and Nature Conservation Research and Development Center, Bogor, had an objective to know the effect of parent cocoon weight on the egg and larval quality among four reciprocal crosses. Strain 803 (Japanece race) and strain 804 (Chinese race) with different cocoon weight were used as parent stocks. The effect of cocoon weight was evaluated on the economical traits including number of eggs, weight of eggs, hatchability, weight of newly hatched larvae and hatching period through crossing method, wherein parents, F1s and reciprocals were involved. The result showed that number and weight of eggs were significantly different. Maximum number of eggs and maximum weight of eggs were 650 and $0.61 \mathrm{mg}$, respectively, that belongs to $\left(803_{B} x 804_{B}\right)$, heavy cocoon of 803 female crossed with heavy cocoon of 804 male. Strain 803 female influenced those characters. Types of crossing had not an effect on hatchability, weight of newly hatched larvae and hatching period.
\end{abstract}

Key words: silkworm (Bombyx mori L.), crossing, Japanese race, Chinese race, cocoon weight, egg quality

\section{Pendahuluan}

Pembibitan merupakan tahapan penting dalam proses produksi kokon karena salah satu faktor penentu kesuksesan produksi adalah ketersediaan bibit yang berkualitas unggul. Bibit yang unggul diharapkan mampu menghasilkan produksi kokon yang tinggi baik kualitas maupun kuantitasnya. Syarat bibit unggul antara lain; produksi kokon rata - rata per induk 0,5-0,6 kg, jumlah kokon rata - rata per kg 500 - 600 buah, jumlah telur rata - rata per induk 400 - 500 butir dan persentase penetasan minimal $85 \%$ (Brasla dan Matei, 1997).

Keseragaman kualitas kokon dan benang akan meningkatkan kuantitas produksi karena kuantitas produksi ditentukan oleh banyaknya kokon yang mampu atau memenuhi syarat untuk dijadikan benang sutera komersial. Hal ini akan meningkatkan volume penjualan yang berdampak pada pendapatan. Faktor yang menentukan mutu kokon adalah; (1) persentase kokon cacat, (2) bobot kokon per butir dan (3) persentase kulit kokon (Atmosoedarjo et al., 2000)

Keseragaman bobot kokon merupakan hal yang sangat penting juga dalam proses pembibitan karena kokon yang seragam diharapkan dapat menghasilkan telur yang seragam dengan kualitas yang baik. Permasalahan yang muncul sebagai akibat dari hal tersebut adalah ketatnya tingkat seleksi pada pembibitan. Kecenderungan untuk mempertahan- 
kan keseragamam bobot kokon menyebabkan tidak dipakainya bobot ekstrim (bobot besar dan kecil), padahal kokon - kokon tersebut berasal dari galur yang mempunyai kualitas unggul. Ketatnya pemilihan kokon yang seragam akan mengurangi jumlah kokon untuk bahan pembibitan.

Permasalahan di atas mendasari sebuah gagasan untuk mencoba menggunakan bobot ekstrim dalam pembibitan. Hal ini dilakukan sebagai penelitian pendahuluan untuk menginformasikan apakah bobot kokon ekstrim yang berasal dari galur unggul dapat menghasilkan kualitas yang sama baiknya dengan bobot kokon yang biasa digunakan. Informasi ini penting dalam pembibitan karena merupakan langkah awal atau pengetahuan dasar untuk penelitian tentang seleksi bobot kokon selanjutnya, sehingga akan didapatkan sebuah kesimpulan apakah bobot kokon ekstrim ini mempunyai kualitas produksi yang sama dengan bobot kokon rata - rata.

\section{Materi Dan Metode}

Bahan yang digunakan dalam penelitian ini adalah 300 kokon galur 803 (Ras Jepang) dan 300 kokon galur 804 (Ras Cina), hasil pemeliharaan ulat sutera dengan pakan Morus multicaulis $P$. dan $M$. cathayana di Pusat Penelitian dan Pengembangan Hutan dan Konservasi Alam, Bogor. Satu liter formalin $2 \%$ dan dua liter $\mathrm{HCl}$ dengan berat jenis $1,110 \mathrm{~kg} / \mathrm{m} 3$.

Metode penelitian menggunakan rancangan acak lengkap dengan empat perlakuan dan empat ulangan. Perlakuannya adalah; (1) 803B X 804B (aBAB), (2) 804B X 803B (ABaB), (3) $803 \mathrm{~K} X 804 \mathrm{~K}$ (aKAK) dan (4)
804K X 803K (AKaK), keterangan: 803 (a) = galur dari Ras Jepang, 804 (A) = galur dari Ras Cina, (B) = kokon besar, $(\mathrm{K})=$ kokon kecil dan sistem penulisan persilangan di mulai dari betina kemudian jantan.

Tahapan penelitian dimulai dari : (1) pemeliharaan ulat sutera yaitu pemeliharaan ulat kecil (instar satu, dua dan tiga selama 12 hari) dan ulat besar (instar empat dan lima selama 13 hari); (2) pengokonan dan panen kokon, proses pengokonan terjadi pada saat badan ulat sedikit berkurang besarnya, kotorannya menjadi lunak, ulat berhenti makan dan mulai berputar - putar dengan mengangkat kepala dan badannya. Panen kokon dilakukan enam sampai tujuh hari setelah ulat mulai mengokon dengan kondisi pupa, saat kokon dipanen berwarna coklat dengan kulit cukup keras; (3) pengelompokan kokon yang di mulai dari penentuan jenis kelamin pupa (penyayatan ujung kokon) dari 300 kokon galur 803 dan 300 kokon galur 804 kemudian penimbangan berdasarkan jenis kelamin per galur, penyusunan bobot kokon hingga diperoleh 30 kokon dengan bobot terkecil dan terbesar per jenis kelamin dan galur; (4) persilangan antara galur 803 dengan 804 yang dapat dilihat pada Gambar 1, (5) Proses penetasan telur di mulai dari perkawinan selama empat jam (dari jam 08.00), pemisahan jantan dan betina, kemudian betina diletakkan di atas kertas telur yang telah dilapisi tepung kanji, ditutup kertas panel pada suhu $25^{\circ} \mathrm{C}$ dan kelembaban $80 \%$, oviposisi selama semalam (dari jam 12.00 sampai 08.00 hari berikutnya), kemudian telur dicelupkan formalin $2 \%$ selama lima menit dan diangin anginkan sampai kering. Perlakuan 
Kokon Besar

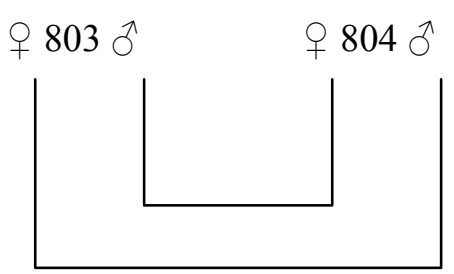

Kokon Kecil

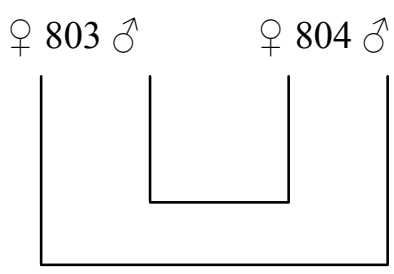

Gambar 1. Sistem Persilangan Ngengat

$\mathrm{HCl}$ dengan berat jenis $1,110 \mathrm{~kg} / \mathrm{m}^{3}$ pada suhu $25^{\circ} \mathrm{C}$ selama $60-120$ menit, kemudian telur dibersihkan dari $\mathrm{HCl}$ dengan air mengalir (sambil dirontokkan) selama sepuluh menit kemudian di inkubasi pada suhu $25^{\circ} \mathrm{C}$ dalam kondisi gelap.

Peubah yang diukur adalah jumlah telur per induk (butir), bobot telur (gram) yaitu bobot telur per induk dibagi jumlah telur per induk, bobot kego (gram) adalah bobot ulat hasil penetasan per induk dibagi jumlah ulat yang baru ditetaskan per induk, daya tetas telur (\%) adalah persentase telur yang menetas dari sejumlah telur fertil, waktu tetas (hari) dimulai dari perlakuan HCL sampai dengan telur menetas.

Data yang diperoleh akan dianalisis dengan sidik ragam (ANOVA), jika perlakuan berpengaruh terhadap peubah yang diukur maka akan dilanjutkan dengan Duncan Multiple Range Test (uji Duncan) untuk melihat perbedaan diantara perlakuan. Data diolah dengan program Minitab (Mattjik dan Sumertajaya, 2002).

\section{Hasil Dan Pembahasan}

\section{Jumlah Telur}

Kisaran jumlah telur pada persilangan resiprokal ini adalah 511,25 - 650,00 butir. Jumlah ini masih dalam kisaran normal karena sesuai dengan pernyataan Brasla dan Matei (1997) telur - telur untuk F1 mempunyai jumlah telur rataan per induk minimal 400 butir.

Persilangan antara galur 803 dan 804 menghasilkan jumlah telur yang berbeda nyata $(\mathrm{p}<0,05)$. Persilangan " $\mathrm{a}_{\mathrm{B}} \mathrm{A}_{\mathrm{B}}$ " menghasilkan jumlah telur terbanyak yaitu 650 butir per induk, sedangkan persilangan lain yaitu " $A_{B} a_{B}$ "; " $A_{K} a_{K}$ " dan " $a_{K} A_{K}$ " menghasilkan jumlah telur yang lebih kecil dan antara ketiga persilangan tersebut mempunyai jumlah rataan yang tidak berbeda nyata.

Tabel 1. Jumlah Telur Hasil Persilangan

\begin{tabular}{cc}
\hline Persilangan & Rataan Jumlah Telur (butir) \\
\hline $\mathrm{a}_{\mathrm{B}} \mathrm{A}_{\mathrm{B}}$ & $650,00^{\mathrm{a}}$ \\
$\mathrm{A}_{\mathrm{B}} \mathrm{a}_{\mathrm{B}}$ & $549,75^{\mathrm{b}}$ \\
$\mathrm{a}_{\mathrm{K}} \mathrm{A}_{\mathrm{K}}$ & $536,67^{\mathrm{b}}$ \\
$\mathrm{A}_{\mathrm{K}} \mathrm{a}_{\mathrm{K}}$ & $511,25^{\mathrm{b}}$ \\
\hline Keterngan:
\end{tabular}

Keterangan: Huruf yang berbeda pada kolom kedua menunjukkan perbedaan nyata $(\mathrm{P}<0,05)$ 
Samsijah dan Kusumaputra (1978) menyatakan bahwa Ras Jepang menghasilkan ngengat yang mempunyai kemampuan bertelur banyak. Data rataan jumlah telur pada Tabel 1 menunjukkan bahwa persilangan yang menggunakan betina galur 803 jumlah telurnya relatif lebih banyak dibanding persilangan yang menggunakan betina galur 804. Ini membuktikan bahwa pengaruh betina untuk galur 803 dengan sifat bertelur banyak lebih mempengaruhi jumlah telur.

Gowda et al. (1989) menyatakan adanya hubungan yang positif antara bobot kokon dan bobot pupa serta bobot pupa terhadap produksi telur (Jayaswal et al., 1991). Artinya bobot kokon yang tinggi akan menghasilkan telur yang banyak dan sebaliknya bobot kokon yang rendah akan menghasilkan jumlah telur yang sedikit. Pernyataan di atas tidak sesuai dengan data pada Tabel 1 karena kokon besar dengan betina galur 804 jumlah telurnya tidak berbeda nyata dengan kelompok kokon kecil dengan betina 804 dan betina galur 803 . Jumlah telur hanya berbeda nyata $(\mathrm{p}<0,05)$ pada kelompok bobot kokon besar yang menggunakan betina galur 803. Hal ini menunjukkan bahwa jumlah telur lebih dipengaruhi oleh sifat betina maternal effect bukan karena kelompok bobot kokon.

\section{Bobot Telur}

Persilangan resiprokal antara galur 803 dan 804 berdasarkan bobot kokon menghasilkan bobot telur yang berbeda nyata $(\mathrm{p}<0,05)$. Rataan bobot telur yang tertinggi adalah " $\mathrm{a}_{\mathrm{B}} \mathrm{A}_{\mathrm{B}}$ " sebesar 0,61 mg. Hal ini terjadi karena Ras Jepang mempunyai ketebalan korion yang lebih tinggi daripada Ras Cina (Brasla dan Matei, 1997).

Salah satu bagian dari telur ulat sutera adalah kulit telur (korion). Korion mempunyai bobot $10 \%$ dari bobot telur dan ketebalan sekitar 0,02 $\mathrm{mm}$ sesuai dengan rasnya. Ini menunjukkan bahwa ketebalan dan bobot korion akan mempengaruhi bobot telur, tetapi dalam penelitian ini pengaruh tebal korion Ras Jepang hanya terjadi pada persilangan yang menggunakan betina galur 803 (" $a_{B} A_{B}$ " dan " $a_{K} A_{K}$ ") baik kelompok bobot kokon besar maupun kecil, tidak pada persilangan yang menggunakan jantan galur 803 (" $A_{B} a_{B}$ " dan " $A_{K} a_{K}$ ") baik pada kelompok bobot kokon besar maupun kecil. Jadi bobot telur yang ditampilkan pada Tabel 2 lebih dipengaruhi oleh sifat betina galur 803 yaitu adanya maternal effect pada persilangan. Pengaruh maternal diduga terjadi karena pola pewarisan sifat tetua jantan dan betina terekspresi berbeda pada zuriatnya (Kasip, 2001).

Tabel 2. Bobot Telur Hasil Persilangan

\begin{tabular}{cc}
\hline Persilangan & Rataan Bobot Telur $(\mathrm{mg})$ \\
\hline $\mathrm{a}_{\mathrm{B}} \mathrm{A}_{\mathrm{B}}$ & $0,61^{\mathrm{a}}$ \\
$\mathrm{A}_{\mathrm{B}} \mathrm{a}_{\mathrm{B}}$ & $0,52^{\mathrm{b}}$ \\
$\mathrm{a}_{\mathrm{K}} \mathrm{A}_{\mathrm{K}}$ & $0,58^{\mathrm{ab}}$ \\
$\mathrm{A}_{\mathrm{K}} \mathrm{a}_{\mathrm{K}}$ & $0,54^{\mathrm{b}}$ \\
\hline
\end{tabular}

Keterangan: Huruf yang berbeda pada kolom kedua menunjukkan perbedaan nyata $(\mathrm{P}<0,05)$ 
Tabel 3. Bobot Kego Hasil Persilangan

\begin{tabular}{cc}
\hline Persilangan & Rataan Bobot Tetas $(\mathrm{mg})$ \\
\hline $\mathrm{a}_{\mathrm{B}} \mathrm{A}_{\mathrm{B}}$ & 0,452 \\
$\mathrm{~A}_{\mathrm{B}} \mathrm{a}_{\mathrm{B}}$ & 0,461 \\
$\mathrm{a}_{\mathrm{K}} \mathrm{A}_{\mathrm{K}}$ & 0,423 \\
$\mathrm{~A}_{\mathrm{K}} \mathrm{a}_{\mathrm{K}}$ & 0,406 \\
\hline
\end{tabular}

Tabel 4. Daya Tetas Telur Hasil Persilangan

\begin{tabular}{cc}
\hline Persilangan & Rataan Daya Tetas (\%) \\
\hline $\mathrm{a}_{\mathrm{B}} \mathrm{A}_{\mathrm{B}}$ & 99,3 \\
$\mathrm{~A}_{\mathrm{B}} \mathrm{a}_{\mathrm{B}}$ & 89,6 \\
$\mathrm{a}_{\mathrm{K}} \mathrm{A}_{\mathrm{K}}$ & 94,1 \\
$\mathrm{~A}_{\mathrm{K}} \mathrm{a}_{\mathrm{K}}$ & 88,9 \\
\hline
\end{tabular}

\section{Bobot Kego}

Persilangan resiprokal galur 803 dan galur 804 menghasilkan bobot kego tidak berbeda nyata $(p>0,05)$ yaitu antara $0,406-0,461 \mathrm{mg}$. Hal ini berarti bahwa sistem persilangan tidak mempengaruhi bobot kego. Respon bobot kego ternyata tidak sejalan dengan bobot telur. Meskipun bobot telur berbeda nyata (Tabel 2) ternyata tidak menyebabkan perbedaan pada bobot kego (Tabel 3).

Keseragaman bobot kego lebih dipengaruhi oleh perlakuan selama masa inkubasi. Suhu dan kelembaban selama masa inkubasi cukup optimum yaitu $25^{\circ} \mathrm{C}$ dan kelembaban $75 \%$ sesuai dengan pernyataan Anwar et al. (1993) bahwa suhu $25-26{ }^{\circ} \mathrm{C}$ pada kelembaban $75-80 \%$ akan mengoptimalkan perkembangan embrio dan kondisi komponen di dalam telur. Kondisi komponen telur yang baik akan mendukung optimalisasi embrio, karena makanan utama embrio adalah yolk (vitelus) yang merupakan salah satu komponen dalam telur.

\section{Daya Tetas}

Data pada Tabel 4 menunjukkan daya tetas yang tidak berbeda nyata ( $p>0,05)$ pada perlakuan persilangan yaitu 88,9 - 99,3 \%. Ini menunjukkan bahwa sistem persilangan berdasarkan bobot kokon tidak berpengaruh nyata pada daya tetas.

Daya tetas dari hasil persilangan resiprokal galur 803 dan galur 804 yang ditunjukkan pada Tabel 4 masih berada dalam kisaran normal karena sesuai dengan daya tetas yang dikemukakan Brasla dan Matei (1997) yaitu minimal $85 \%$. Sistem penanganan telur yang seragam pada perlakuan persilangan akan menghasilkan daya tetas yang seragam. Daya tetas lebih dipengaruhi oleh penanganan telur. Perlakuan HCL akan merangsang proses penetasan sehingga dengan perlakuan yang sama diharapkan dapat menghasilkan keseragaman penetasan dan persentase penetasan (Samsijah dan Kusumaputra, 1978). Pembersihan telur dari $\mathrm{HCl}$ juga berpengaruh terhadap daya tetas. Perlakuan yang 
kasar pada telur akan menyebabkan kerusakan komponen telur sehingga dapat menurunkan daya tetas. Suhu dan kelembaban yang optimum yaitu $25^{\circ} \mathrm{C}$ dan kelembaban $75-80 \%$ dapat mendukung proses penetasan karena dapat mempengaruhi perkembangan embrio di dalam telur.

\section{Waktu Tetas}

Data waktu tetas hasil persilangan resiprokal pada Tabel 5 menunjukkan tidak berbeda nyata $(p>0,05)$ pada perlakuan persilangan yaitu 10 hari 16 jam sampai dengan 11 hari 6 jam. Hal ini terjadi karena waktu tetas lebih dipengaruhi oleh faktor lingkungan, misalnya suhu dan kelembaban.

Suhu dan kelembaban yang optimal selama penanganan telur dan inkubasi akan merangsang proses penetasan. Ini berarti akan mendukung perkembangan dari embrio, sehingga

Tabel 5. Waktu Tetas Hasil Persilangan akan menghasilkan waktu tetas yang seragam. Suhu $25^{\circ} \mathrm{C}$ dan kelembaban $75 \%$ selama masa inkubasi pada penelitian ini sesuai dengan suhu optimum masa inkubasi telur menurut Anwar et al. (1993). Waktu tetas yang dihasilkan pada Tabel 7 masih dalam kisaran waktu tetas yang dikemukakan Pusat Penelitian dan Pengembangan Hutan (1992) yaitu 9 - 10 hari untuk jenis polivoltine dan persilangannya, serta 9 - 12 hari untuk jenis bivoltine. Sementara jenis yang dipakai pada penelitian ini adalah jenis bivoltine.

\section{Pemilihan Persilangan Terbaik}

Berdasarkan hasil persilangan resiprokal galur 803 dan galur 804 pada Tabel 1, 2, 3, 4 dan 5 dapat dipilih sistem persilangan yang paling baik pada penelitian ini. Daftar persilangan hasil terbaik dari setiap sistem persilangan dapat dilihat pada Tabel 6 .

\begin{tabular}{cc}
\hline Persilangan & Rataan Waktu Tetas (hari) \\
\hline $\mathrm{a}_{\mathrm{B}} \mathrm{A}_{\mathrm{B}}$ & 11,25 \\
$\mathrm{~A}_{\mathrm{B}} \mathrm{a}_{\mathrm{B}}$ & 10,75 \\
$\mathrm{a}_{\mathrm{K}} \mathrm{A}_{\mathrm{K}}$ & 10,67 \\
$\mathrm{~A}_{\mathrm{K}} \mathrm{a}_{\mathrm{K}}$ & 11,25 \\
\hline
\end{tabular}

Tabel 6 Daftar Hasil dari Setiap Sistem Persilangan

\begin{tabular}{cccccc}
\hline Persilangan & $\begin{array}{c}\text { Jumlah } \\
\text { Telur }\end{array}$ & $\begin{array}{c}\text { Bobot } \\
\text { Telur }\end{array}$ & $\begin{array}{c}\text { Bobot } \\
\text { Kego }\end{array}$ & Daya Tetas & $\begin{array}{c}\text { Waktu } \\
\text { Tetas }\end{array}$ \\
\hline $\mathrm{a}_{\mathrm{B}} \mathrm{A}_{\mathrm{B}}$ & $\mathrm{A}$ & $\mathrm{A}$ & th & th & th \\
$\mathrm{A}_{\mathrm{B}} \mathrm{a}_{\mathrm{B}}$ & $\mathrm{B}$ & $\mathrm{B}$ & th & th & th \\
$\mathrm{A}_{\mathrm{K}} \mathrm{a}_{\mathrm{K}}$ & $\mathrm{B}$ & $\mathrm{B}$ & th & th & th \\
$\mathrm{a}_{\mathrm{K}} \mathrm{A}_{\mathrm{K}}$ & $\mathrm{B}$ & $\mathrm{Ab}$ & tn & tn & th \\
\hline
\end{tabular}

Keterangan: (a,b) Huruf yang berbeda pada kolom dua dan tiga menunjukkan perbedaan nyata $(\mathrm{p}<0,05),($ tn $)$ menunjukkan nilai tidak berbeda nyata $(\mathrm{p}>0,05)$. 
Pada Tabel 6 terlihat bahwa jumlah dan bobot telur berbeda nyata pada setiap sistem persilangan. Sistem persilangan " $\mathrm{a}_{\mathrm{B}} \mathrm{A}_{\mathrm{B}}$ " menghasilkan jumlah telur terbanyak sebesar 650 butir per induk (Tabel 1), bobot telur tertinggi sebesar $0,61 \mathrm{mg}$ per butir (Tabel 2) serta bobot kego, daya tetas dan waktu tetas yang tidak berbeda nyata dengan sistem persilangan yang lain $\left(A_{B} a_{B}, A_{K} a_{K}, a_{K} A_{K}\right)$. Kondisi di atas menjadi dasar pemilihan sistem persilangan terbaik karena dengan kondisi tersebut diharapkan sistem persilangan " $\mathrm{a}_{\mathrm{B}} \mathrm{A}_{\mathrm{B}}$ " akan menghasilkan jumlah produksi kokon yang tinggi. Hal ini menunjukkan bahwa sistem persilangan yang paling baik dalam penelitian ini adalah " $\mathrm{a}_{\mathrm{B}} \mathrm{A}_{\mathrm{B}}$ ".

\section{Kesimpulan}

Sistem persilangan resiprokal antara galur 803 dan 804 berdasarkan bobot kokon berpengaruh terhadap jumlah dan bobot telur, tetapi tidak berpengaruh terhadap bobot kego, daya tetas dan waktu tetas. Sistem persilangan " $\mathrm{a}_{\mathrm{B}} \mathrm{A}_{\mathrm{B}}$ " menghasilkan jumlah rataan telur tertinggi 650 butir per induk dan rataan bobot telur tertinggi 0,61 mg per butir, sedangkan sistem persilangan lain " $A_{B} a_{B}$ ", "A $\mathrm{K}_{K}$ ", " $\mathrm{a}_{\mathrm{K}} \mathrm{A}_{\mathrm{K}}$ " menghasilkan jumlah dan bobot telur yang lebih rendah. Sistem persilangan tidak berpengaruh terhadap bobot kego, daya tetas dan waktu tetas. Sistem persilangan terbaik pada penelitian ini adalah sistem persilangan pada kelompok bobot kokon besar dengan betina galur 803 dan jantan 804 ("a $\mathrm{a}_{\mathrm{B}} \mathrm{A}_{\mathrm{B}}$ ").

\section{Daftar Pustaka}

Atmosoedarjo, S., J. Kartasubrata, W. Saleh, M. Kaomini dan W.
Moerdoko. 2000. Sutera Alam Indonesia. Yayasan Sarana Wana Jaya, Jakarta.

Anwar, A., A. P. Saranga, B. Hartoko, B. Sampe dan N. L. Allo. 1993. Pedoman Peningkatan Mutu Bibit Induk Ulat Sutera. Balai Persuteraan Alam, Ujung Pandang.

Brasla, A. dan A. Matei. 1997. Pelatihan Pembibitan Ulat Sutera II oleh Ahli dari Rumania. PPUS Candiroto, Temanggung, Jawa Tengah.

Gowda, B. L. V., T. K. Narayanaswamy and R. Munirajappa. 1989. Impact of pupal weight on growth and development of the following generation in the silkworm Indian race NB7 (Bombyx mori). Seri-cologia. 29:481-489.

Jayaswal, K. P., T. Singh and G. S. Rao. 1991. Effect of female pupal weight on fecundity of mulberry silkworm, Bombyx mori. Indian J. Sericologia 30:141-143.

Kasip, L. M. 2001. Pembentukan Galur Baru Ulat Sutera (Bombyx mori L.) melalui Persilangan Ulat Sutera Bivoltin dan Polivoltin. Disertasi. Program Pascasarjana. Institut Pertanian Bogor, Bogor.

Pusat Penelitian dan Pengembangan Hutan. 1992. Petunjuk Teknis Budidaya Ulat Sutera. Departemen Kehutanan, Bogor.

Mattjik, A. A. dan I. M. Sumertajaya. 2002. Perencanaan Percobaan. Jilid I. Edisi Kedua. IPB Press, Bogor.

Samsijah dan A. S. Kusumaputra. 1978. Pembibitan Ulat Sutera. Lembaga Penelitian Hutan, Bogor. 
Steel, R. D. G. dan J. H. Torrie. 1993. Terjemahan: B. Sumantri. PT.

Prinsip dan Prosedur Statistika: Gramedia Pustaka Utama,

Suatu Pendekatan Geometrik. Jakarta.

Alamat Korespondensi: Y.C. Endrawati

Departemen Ilmu Produksi dan Teknologi Peternakan Fakultas Peternakan IPB

Jl. Agatis, Kampus IPB Darmaga

BOGOR

Telp.:

Artikel diterima tanggal: 23 Januari 2006 dan disetujui tanggal 14 Mei 2006. 